\title{
A Case of Reactive Eccrine Syringofibroadenoma
}

\author{
Eujin Cho, M.D., Jeong Deuk Lee, M.D., Sang Hyun Cho, M.D. \\ Department of Dermatology, College of Medicine, The Catholic University of Korea, Seoul, Korea
}

Eccrine syringofibroadenoma is a rare adnexal tumor of eccrine ductal differentiation with variable clinical features. It manifests as either a solitary or multiple papules and nodules arranged in a symmetrical or linear pattern. The anatomical distribution is wide and includes the face, trunk, extremities, and rarely the nails. Histopathological findings show anastomosing cords and strands of uniform cuboidal cells surrounded by fibrovascular stroma. Herein, we report a case of reactive eccrine syringofibroadenoma which developed on the foot of a 37-year-old woman, after self-paring of tissue and subsequent infection and ulceration.

(Ann Dermatol 23(1) 70 72, 2011)

\section{-Keywords-}

Reactive eccrine syringofibroadenoma, Ulcer

\section{INTRODUCTION}

Eccrine syringofibroadenoma (ESFA) is a rare tumor of eccrine ductal differentiation with variable clinical findings and characteristic histological features. Five clinical subtypes have been reported: 1) multiple ESFA associated with hidrotic ectodermal dysplasia, 2) multiple ESFA without associated cutaneous features, 3) unilateral linear ESFA, 4) solitary ESFA, and 5) reactive ESFA ${ }^{1,2}$. Reactive ESFA represents an epithelial change in association with other inflammatory or neoplastic dermatoses such as chronic skin ulcers ${ }^{3}$, burn scars ${ }^{4}$, lepromatous neuropathy, venous stasis, bullous pemphigoid, erosive palmoplantar lichen planus, peristomal dermopathy, nevus sebaceous, and pre-existing malignant tumors such

Received November 4, 2009, Revised January 26, 2010, Accepted for publication March 8, 2010

Corresponding author: Sang Hyun Cho, M.D., Department of Dermatology, Incheon St. Mary's Hospital, 665 Bupyung-dong, Bupyung-gu, Incheon 403-720, Korea. Tel: 82-32-510-5528, Fax: 82-32-506-9514, E-mail: drchos@yahoo.co.kr as sqaumous cell carcinoma. About 75 cases of ESFA have been reported in the English literature to date, and 18 of the cases $(24 \%)$ were diagnosed as reactive ESFA ${ }^{5}$.

\section{CASE REPORT}

A 37-year-old woman presented with painful, multiple, coalescing, flesh-colored nodules forming a plaque on the left foot that had persisted for two years. The patient reported that the skin lesion developed several months after self-paring of a toughened area of skin on the lateral aspect of her left foot; the patient thought it was a callus. After paring, her left foot became infected, with discharge and an ulcer that was $1.5 \times 1 \mathrm{~cm}$ in size. Bacterial culture of the lesion showed growth of Escherichia coli and Pseudomonas aeruginosa. The patient was admitted to the orthopedic department and was treated with antibiotics and debridement. However, the ulcer did not heal appropriately and was covered by an overlying keratotic, verrucous plaque. The plaque gradually increased in size. The patient had a history of gestational diabetes mellitus in 2006, with no other notable findings in her past. No similar lesions were reported among family members.

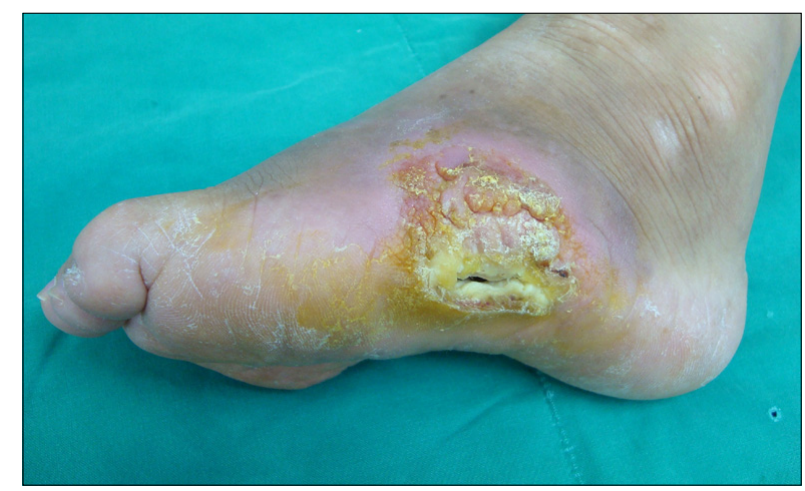

Fig. 1. Multiple, coalescing, firm, flesh-colored nodules associated with areas of crusting on the left foot. The nodules show a 'streusel bread'-like surface. 

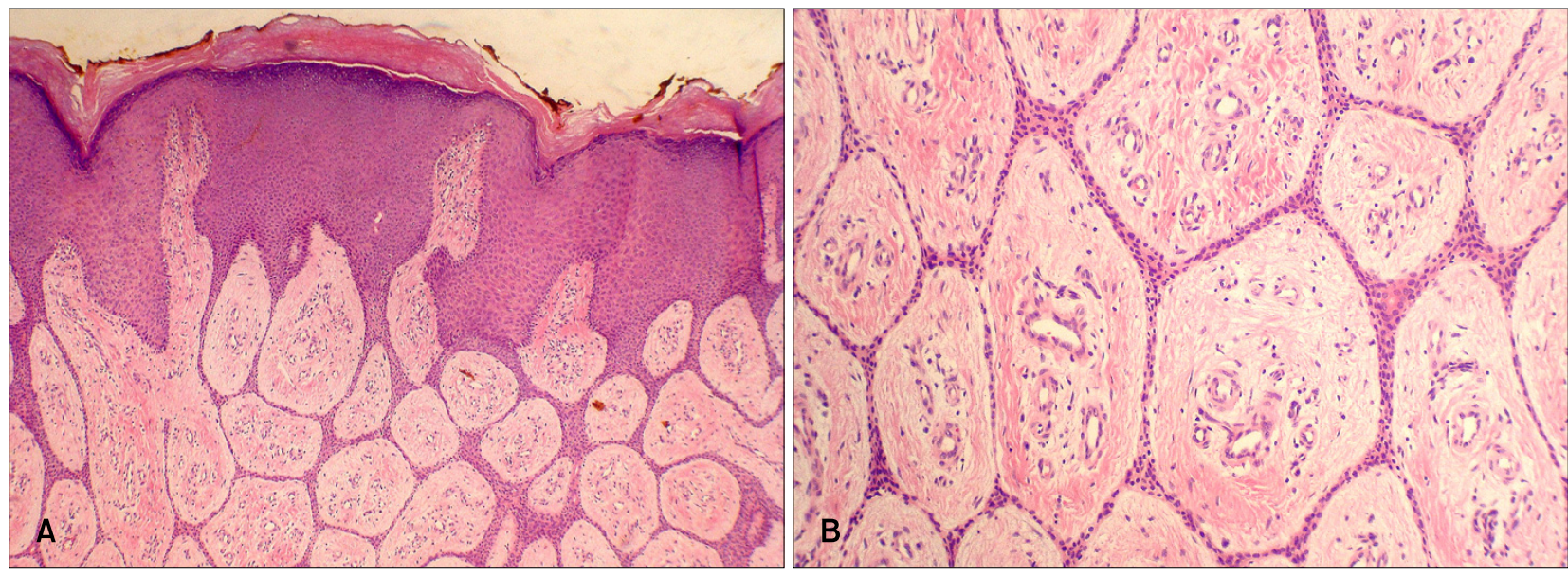

Fig. 2. (A) On histopathological examination, thin anastomosing strands of uniform, small epithelial cells arising from the epidermis to the dermis were observed $(\mathrm{H} \& \mathrm{E}, \times 40)$. (B) The cells were embedded in a cellular fibrous stroma and exhibited a latticed pattern characteristic of eccrine syringofibroadenoma $(H \& E, \times 100)$.

Cutaneous examination revealed multiple, coalescing, firm, flesh-colored nodules in a 'streusel bread'-like appearance, associated with areas of crusting (Fig. 1). On histopathological examination, thin anastomosing strands of uniform, small, epithelial cells arising from the epidermis to the dermis were observed (Fig. 2A). The cells were embedded in a cellular fibrous stroma and exhibited a latticed pattern characteristic of ESFA (Fig. 2B). Luminal structures were observed within the strands, and there were no cytological abnormalities. Some fungal hyphae were also observed in the corneal layer. The patient was referred to the orthopedic department and was treated with antibiotics and total excision of the cutaneous lesion.

\section{DISCUSSION}

ESFA is an uncommon tumor of eccrine glands that was first described by Mascaro $^{6}$ in 1963. ESFA usually manifests as a solitary nodule on the extremities of an elderly person. Other sites of occurrence include the face, trunk and rarely the nails. Clinical findings are variable, ranging from solitary nodules to multiple papules, nodules, and plaques. Starink ${ }^{1}$ classified ESFA into four clinical subtypes: 1) multiple ESFA associated with hidrotic ectodermal dysplasia, 2) multiple ESFA without associated cutaneous features, 3) unilateral linear ESFA, 4) solitary ESFA, and French ${ }^{2}$ subsequently proposed the fifth subtype, reactive ESFA.

The diagnosis of ESFA is based on its characteristic histopathological findings. Histologically, ESFA is remarkably similar. The findings typically show proliferation of anastomosing strands and cords of monomorphous epithelial cells in a reticular pattern with eccrine duct formations embedded in a fibrovascular stroma. The histologic differential diagnosis includes fibroepithelial tumor of Pinkus, tumor of the follicular infundibulum, pseudoepitheliomatous hyperplasia, papillary eccrine adenoma, reticulated seborrheic keratosis, squamous cell carcinoma, and artifacts of histologic processing ${ }^{7}$.

It is still unclear whether the lesion is hyperplastic, hamartomatous, or neoplastic in nature. Some investigators have suggested that ESFA is a disorder that manifests as a spectrum of clinical findings, rather than being separate in nature $^{8}$. The potential of progression of hyperplastic, hamartomatous, benign neoplastic, and malignant changes has been proposed, however this process has not been consecutively demonstrated in every case.

Reactive ESFA has rarely been reported in association with a chronic ulcer $^{3}$ and a burn scar ulcer ${ }^{4}$. Considering our patient's history of self-paring tissue manipulation followed by infection and ulceration, reactive ESFA was the most likely diagnosis in this case. The suggested pathogenesis of reactive ESFA includes repeated eccrine duct trauma resulting in eccrine duct remodeling and repair ${ }^{7}$. Our patient demonstrates the first case of reactive ESFA in Korea.

The clinical course of ESFA is typically benign. However, malignant transformation to eccrine syringofibrocarcinoma and the association with squamous cell carcinoma has been reported in cases of ESFA ${ }^{9}$. A gradual increase in size, pain, ulcer and crust formation, and persistent lesions despite extensive treatments have been associated with malignant changes ${ }^{7}$.

The excision of the lesion has been the mainstay of treatment for solitary ESFA since malignant transformation of ESFA lesions has been reported ${ }^{9}$. Since the risk is low, 
however, close observation and follow-up may be an alternative to early excision, especially when complete excision is difficult due to involvement of larger areas. Since ulcers are common cutaneous findings in the dermatology department, physicians should consider ESFA and its malignant potential in the differential diagnosis of similar lesions developing from a skin ulcer.

\section{REFERENCES}

1. Starink TM. Eccrine syringofibroadenoma: multiple lesions representing a new cutaneous marker of the Schopf syndrome, and solitary nonhereditary tumors. J Am Acad Dermatol 1997;36:569-576.

2. French LE. Reactive eccrine syringofibroadenoma: an emerging subtype. Dermatology 1997;195:309-310.

3. Utani $A$, Yabunami $H$, Kakuta $T$, Endo $H$, Shinkai $H$. Reactive eccrine syringofibroadenoma: an association with chronic foot ulcer in a patient with diabetes mellitus. J Am
Acad Dermatol 1999;41:650-651.

4. Ichikawa E, Fujisawa Y, Tateishi Y, Imakado S, Otsuka F. Eccrine syringofibroadenoma in a patient with a burn scar ulcer. Br J Dermatol 2000;143:591-594.

5. Poonawalla T, Xia L, Patten S, Stratman EJ. Clouston syndrome and eccrine syringofibroadenomas. Am J Dermatopathol 2009;31:157-161.

6. Mascaro JM. Considerations on fibro-epithelial tumors. Exocrine syringofibradenoma. Ann Dermatol Syphiligr (Paris) 1963;90:143-153.

7. Mattoch IW, Pham N, Robbins JB, Bogomilsky J, Tandon M, Kohler S. Reactive eccrine syringofibroadenoma arising in peristomal skin: An unusual presentation of a rare lesion. J Am Acad Dermatol 2008;58:691-696.

8. Tey HL. Characterizing the nature of eccrine syringofibroadenoma: illustration with a case showing spontaneous involution. Clin Exp Dermatol 2009;34:e66-e68.

9. Cho HS, Kim WH, Kim CW, Kim KH, Kim KJ. A case of eccrine syringofibroadenoma associated with squamous cell carcinoma. Korean J Dermatol 2005;43:1635-1638. 